\title{
El recurso de Roma al bandidaje hispano
}

\author{
Margarita Vallejo Girvés *
}

La lectura de las obras de los autores antiguos que se ocupan total o parcialmente de aspectos geográficos y humanos de la Península lbérica revela la aparición de varias constantes en su percepción de la misma, tales como la riqueza de una parte de Hispania comparada inmediatamente con la pobreza y la aridez de otra; como la recurrente alusión a los orígenes míticos de las gentes de lberia y por supuesto a la fiereza, al salvajismo, a la bravura de sus gentes, en definitiva a su barbarie, obviamente vistos estos calificativos dentro de la perspectiva del autor que considera a su propia forma de vida como prácticamente la única civilizada, en contraposición a aquellas cuyas caracteristicas, por estar alejadas de las romanas, impiden calificarlas de tal forma ${ }^{1}$.

En íntima relación con la utilización por estos autores de dichos calificativos para presentar a las gentes con las que Roma debía enfrentarse en las tierras peninsulares encontramos constantes referencias a la práctica del bandidaje, del bandolerismo, por parte de muchas de las gentes hispanas; éstas son en definitiva presentadas en diversas ocasiones como latrones, como praedones, en suma como practicantes del latrocinium en una de sus diversas acepciones: el saqueo sobre bienes ajenos ${ }^{2}$.

* Universidad de Alcalá de Henares.

Este artículo se ha realizado dentro del marco del Proyecto de Investigación «La visión de Hispania por Griegos y Romanos. Mito, prejuicios e ideología como marco de percepción cultural», financiado por la Universidad de Alcalá de Henares.

Vid. F.J. Gómez Espelosín, M. Vallejo Girvés y a. Pérez Largacha, la imagen de España en la Antigüedad Clásica, ed. Gredos, Madrid 1995 (en prensa).

2 Sobre las distintas acepciones e implicaciones jurídicas de éste véase, entre otros, G. HUMberT, CH. LeCrivain, s.v. "latrocinium", en Dictionnaire des Antiquités Grecques et Romaines, ed. Ch.Daremberg,Edm. Saglio.Edn. Pottier III/2, 991-992; E. DE RuGGIERo, Dizionario Epigrafico di Antichità Romane, vol. IV, fasc. 15, Roma 1947, s.v. «Latrones», 460-466; Pfaff, s.v. «latrocinium», 
En sus obras estos autores parecen estar al tanto de las diversas motivaciones que podían conducir a estas gentes a buscar su sustento diario mediante esta forma de vida, que consistiria, como ha consistido siempre, en la apropiación, las más de las veces de forma violenta y por supuesto totalmente contraria al comportamiento correcto y ordenado - que era evidentemente definido desde Roma-, de bienes ajenos ${ }^{3}$.

Como cabe suponer no se trata éste de un fenómeno exclusivamente peninsular ya que en la literatura grecorromana no son pocas las ocasiones en que se encuentran alusiones al mismo localizadas en áreas con las que Roma, en uno u otro momento, empieza a tomar contacto. Así podemos referirnos, entre otros muchos, al pasaje de Estrabón XVI, 1, 17-18, tocante a las áreas montañosas de Media y Partia; al de Varrón, De Re Rustica I, 16, para Cerdeña, o al de Floro II, 25, para los dálmatas ${ }^{4}$.

Sin embargo un elemento relacionado con Hispania, dentro de esta misma temática, sí nos parece altamente peculiar y por ello no deja de sorprendernos; nos referimos a que en diversas ocasiones se califica a pueblos enteros e incluso a la totalidad de los íberos - dejemos al margen cualquier significación étnica de este término- como particularmente amantes del latrocinium en la acepción a la que nos hemos referido ${ }^{5}$.

Veámos cuáles son en este sentido algunos de los casos más significativos: por ejemplo encontramos que Plutarco, con ocasión de su narración del episodio en que Cayo Mario decide ocuparse del bandolerismo de la

RE XII, 1, cols. 978-980.También L. Flam-Zuckerman, “A propos d' une inscription de Suisse (C/L $X I I I, 5010$ ). Étude du phénomène du brigandage dans l' Empire romain», Latomus 1970, 456 y $\mathrm{M}$. CLAVEL-LÉVÉQUE, «Brigandage et piraterie: représentation idéologiques et pratiques impérialistes au dernier siècle de la Republique», DHA 4, 1978, 17-31.

L. FLAM-ZUCKERMANN, art. cit., 457-559.

4 Véase M. Gras, «Les Montes Insani de la Sardaigne», en ed. R. Chevalier, Mélanges offerts a Roger Dion, Caesarodunum IX bis, París 1974, 358-359, para Cerdeña; F.J. LoMAs, «Bárbaros y Barbarie en Estrabón», I Congreso Andaluz de Estudios Clásicos, Jaén 1981 (1982), 17, para áreas orientales. $C f$. en términos generales, B.D. SHAw, «Bandits in the Roman Empire», Past and Present 105, 1874, 24.

5 No podemos aquí ocuparnos de las distintas causas apuntadas para la existencia del fenómeno del bandidaje hispano, por ello nos remitimos a la bibliografía orientativa que a continuación citamos: L. FLAM-ZuCKERMANN, art. cit., 463; S.L. DySON, The Creation of the Roman Frontier, Princeton 1985, 207-208; Id., "Native Revolis Patterns in the Roman Empire», ANRW II, 3, 1975, 138-175; E. HoBsBAwn, Rebeldes primitivos. Estudios sobre las formas arcaicas de los movimientos sociales en los siglos $X I X$ y $X X$, trad. esp. Esplugas de Llobregat 1974; A. GARCIA Y BELLIDO, "Bandas y guerrillas en las luchas con Roma», en AA.VV., Conflictos y estructuras sociales en la Hispania Antigua, (ed. A. Prieto Arciniega), Madrid 1986, 17-20, incidiendo en una motivación económica. Y en un sentido contrario e innovador, M.V. GARcia QuINTELA, «Sources pour l' étude de la protohistorie d' Hispania. Pour une nouvelle lecture», DHA 17.1, 1991, 61-99, que defiende el sentido iniciático de esta actividad. 
Ulterior, extiende el fenómeno y concluye que los íberos de aquel tiempo no dudaban de que el bandidaje era la más bella de las ocupaciones ${ }^{6}$; igualmente Estrabón III, 4, 5, que después de calificar a los íberos de tercos y de naturaleza pérfida, concluye que son guerreros pero también, algo peor, bandoleros y bandidos; y el muy significativo de Tito Livio XXVIII, 32, 8-9, al calificar a la totalidad de los ilergetes simplemente como bandidos y jefes de bandidos, en un sentido claramente despectivo y despreciatorio, pues según éste tan sólo eran capaces de robar e incendiar, escondiéndose a continuación sin presentar combate alguno.

Estos testimonios pueden ciertamente explicarse pensando que ante la que parece innegable extensión de esta práctica entre varios pueblos peninsulares y lo dañinas que resultaron sus consecuencias para Roma, se llegara a presentarlo por parte de algunos autores -tardíos en relación a los acontecimientos que se relatan-como común a buena parte de las gentes de la Hispania indígena, convirtiéndose de este modo la calificación al hispano como bandido en uno más de los tópicos que le eran asignados por aquellos relacionados con la potencia romana.

Sin embargo consideramos igualmente posible que la que nos parece excesiva extensión del bandidaje peninsular podría comprenderse atendiendo a la instrumentalización política e ideológica con la que Roma presenta su conducción de la conquista peninsular ${ }^{7}$.

¿Cuáles pudieron ser, desde este punto de vista, alguno de los motivos que indujeron a presentar en diversas ocasiones a los pueblos hispanos como simples bandidos, a los que ni tan siquiera era posible presentar como enemigos, un calificativo que implicaba mayor prestigio, tal como se desprende de Tito Livio XXX, 7,6 ? $^{8}$.

En este sentido debemos recordar, como ha hecho recientemente M. V. García Quintela, la no contemporaneidad de muchos de estos autores a los hechos que van a relatar y por consiguiente la mediatización que debió ejercer sobre ellos la «ideología de la Pax Romana» al dibujar un mundo romano en el que estaba ausente el fenómeno bélico ${ }^{9}$. Pero además en nuestra opinión todo ello podría estar también relacionado con la presentación de las pautas romanas como sinónimas de las civilizadas y de la

Plut, Mar., 6.

Cfr. L.A. García Moreno, "Presupuestos ideológicos de la actuación de Roma durante el proceso de la conquista de Hispania», Gerion 5, 1987, 230-233.

8 Cfr. B.D. SHAW, art. cit, 6-7.

9 M.V. Garcia QuinTelA, art. cit., $94-96$ y n. 98. 
continuidad de la lucha de Roma en la Península como la única posibilidad de que ésta se integrara en el mundo ordenado ${ }^{10^{\circ}}$.

Roma, la civilización, se caracterizaba por una forma de vida tranquila y ordenada, que se conducía de acuerdo a unas normas que precisamente eran las que definían aquella, frente a la mayoría de formas de comportamiento que acabarán siendo sinónimas de barbarie.

Era pues responsabilidad de la forma de vida civilizada y consecuentemente situada en un plano superior, económico, político, social, moral y religioso, conducir a estos desviados a las pautas vitales correctas ${ }^{11}$. Puesto que éstos se caracterizaban por su belicosidad, por su fiereza, por su bravura y por su negativa a aceptar cualquier elemento que les fuera impuesto, la civilización se vería obligada a utilizar el recurso legítimo de la fuerza para, una vez domeñados, conducirlos por el buen sendero.

En el caso hispano, sin embargo, Roma no pudo convencerles totalmente de que debian cambiar de vida y aceptar la sumisión de buen grado. En su proceso de conquista de la Península por las armas, que debía convertirla en un ámbito totalmente civilizado, encontraron tan enconada resistencia que no deja de ser significativo que para el año 152/151 a. C., Polibio reflejará que, ante el peligro que significaba combatir en Hispania, hubiera surgido en Roma verdadero pavor entre aquellos que debían incorporarse como tribunos y legados a las legiones que alli se dirigían, si bien no podemos tampoco olvidar en este episodio la propia situación social interna de Roma ${ }^{12}$.

\footnotetext{
10 Vid. M. VALLEjo GirvÉs, "Civilización romana y mundo bárbaro» en F.J. Gómez EsPelosín, M. Vallejo Girvés y a. PÉrez Largacha, op. cit.

11 Para esta perspectiva en Estrabón, véase E.C.L. VAN DER VLIET, «L' Ethonographie de Strabon: Idéologie ou tradition?", en F. Prontera (ed.), Strabone. Contributi allo studio della pesonalita e dell' opera, Perugia, 1984, 66-67.

12 Pol., 35, iv., Per. Oxyr. 48; App., Ib. 49. Al parecer los jóvenes ciudadanos romanos se negaron a servir como tribunos militares y legados. Cf. en este sentido los diversos análisis, relacionados con el poder de los tribunos de la plebe en este episodio en particular, de L. R. TAYLOR, «Forerruners of the Gracchi», JRS 52, 1962, 21-22; D.C. EARL, Tiberius Gracchus.A Study in Politics, Col. Latomus 66, Bruselas 1963, 33; E.A. Astin, Scipio Aemilianus, Oxford 1967, 41-45, 135-136, 167-168 y 171, quien cree que el Senado también sentia gran animadversión por la guerra de Hispania; P.A. Brunt, Italian Manpower (225 b. C.-14 a. C.), Oxford 1971, 397-398; Y. SHOCHAT, Recruitment and the Programme of Tiberius Gracchus, Bruselas 1980, 56-57; J.K. EvANs, «Resistance at Home: The Evasion of Military Service in Italy during the Second Century b. C.", T. Yuge \& M. Doi eds., Forms of Control and Subordination in Antiquity, Tokio 1988, 124-125 y n. 27. Una interpretación desde la subjetiva posición polibiana en L.A. GARcía MORENO, «La Hispania anterior a nuestra era: Verdad, ficción y prejuicio en la historiografía antigua y moderna", VII Congreso Español de Estudios Clásicos, Madrid 1987 (1989), vol. III, 25-26.
} 
Es en nuestra opinión en este contexto cuando debemos detenernos a pensar en uno de los posibles motivos de esa extensa calificación de una Iberia poblada de bandidos y bandoleros, aunque seamos conscientes de nuestra exageración, teniendo siempre presente que el bandidaje, con el significado que nos ocupa, era visto por los hombres civilizados, por los romanos, como una lacra y como la forma de vida más despreciable ${ }^{13}$.

El bandidaje era una actividad despreciable no sólo porque los lugares donde generalmente habitaban los actores de tales acciones -montañas, bosques inhóspitos - se mantenían, por definición, fundamentalmente al margen de la civilización ${ }^{14}$ sino porque se apropiaban del esfuerzo de las gentes que vivían o querían vivir bajo la norma de comportamiento establecida ${ }^{15}$.

Es innegable, y así lo reconocen estos autores, que las gentes hispanas fueron capaces de resistir y superar en múltiples ocasiones a la maquinaria militar y civilizadora romana; sin embargo hay que pensar también que la propia población romana podía comenzar a dudar de la fortaleza y de la superioridad de su forma de vida si los hombres destinados a acabar con esa prolongada resistencia habían sido superados abierta y continuamente por unas gentes bárbaras, y consecuentemente consideradas inferiores. ¿Cómo explicar por tanto que un ejército altamente organizado y desarrollado tecnológicamente no hubiera sido capaz de vencer de modo efectivo y duradero a un enemigo teóricamente inferior?

Pensamos que un modo de alcanzar ese objetivo pudo ser la utilización del recurso del sentido negativo de la barbarie y dentro de éste, presentar al enemigo como un bandido, uno de los grados más despreciables de aquella ${ }^{16}$, que llevaba a cabo rápidas incursiones buscando su objetivo pero que, salvo en estas ocasiones, nunca salía de su hábitat natural, la montaña, los bosques, etc... De este modo podía quedar aparentemente justificado el costoso esfuerzo de Roma para apoderarse de amplias zonas hispanas ${ }^{17}$ : muchos de estos resistentes eran bandidos,

13 Cf. Suet., Tib., I., la familia Claudia acordó no llevar el nomen familiar de Lucius porque uno de sus antepasados, llamado así, fue condenado por latrocinium.

${ }_{14}$ Véase. R. MacMullen, Enemies of the Roman Order. Treason, Unrest and Alienation in the Empire., Cambridge (Mass.) 1966, 192-193, y en último término las distintas aportaciones en $\mathrm{G}$. Fabré (dir.), La Montagne dans l' Antiquité, Cahier de l' Université de Pau 1992.

is Véase Liv. XXXIV, xXi, 1; cf. J. MART́́NeZ-GAZQUEZ, "Los praedones de Livio 34, 21, restos de bandas emigrantes en Hispania», Pyrenae 11, 1975, 107.

16 Véase para una extensión de este recurso P. BRIANT, «Brigandage, dissidence et conquête en Asie achéménide et hellénistique», DHA 2, 1976, 182-184.

17 Cfr. en similar sentido J.A. FERnÁndez CANOSA, «Rutura das hostilidades, Alianza e Paz, e Fides na Hispania Pre-romana: Instituizons da Guerra», I Congreso Peninsular de Historia Antigua II, Santiago de Compostela 1986 1988), 247-248. 
seres despreciables y cobardes que nunca hacían frente directamente a las huestes romanas, que sólo lograban resistir a la fuerza de Roma gracias a la abundancia de lugares en la Península donde podían refugiarse ${ }^{18}$, y donde lo inhóspito del terreno en el que se guarnecían hacía imposible que las legiones operasen con el cien por cien de la efectividad que habían demostrado en otras ocasiones.

Además, con el recurso constante a la presentación de algunos pueblos hispanos como bandidos en nuestra opinión podría también lograrse que se comprendiera y admitiera que, a pesar del alto coste, había sido necesario continuar enfrentándose a ellos; además de utilizar el reclamo de la posibilidad de obtención de fama y gloria ${ }^{19}$, podría simplemente exponerse que no era posible permitir que gentes no civilizadas, cuyo oficio era el medrar, superaran a la civilización. Roma no podía permitir que Hispania volviera a caer en su totalidad en las costumbres bárbaras que la habian caracterizado antes de su llegada ${ }^{20}$, costumbres entre las que debía encontrarse necesariamente el latrocinium.

Por otra parte no podemos dejar de pensar en que la presentación del hispano como bandido podía acercar la comprensión del problema a los ojos de aquellos ajenos al ámbito peninsular: el bandidaje era un fenómeno que debía conocerse directamente en los campos itálicos y donde evidentemente el objetivo codiciado sería siempre el mismo: la apropiación de los bienes de los demás; como ejemplo no tenemos más que recordar ciertos aspectos de la problemática ligur con la que se tuvo que enfrentar la República en el siglo II a. C. ${ }^{21}$, o el demostrativo pasaje de Suetonio, Aug. 32, donde habla de la actividad en el área itálica de estas gentes y de los medios que Augusto dispuso para reprimirlos, en este caso, situar diversos puestos y guarniciones en lugares estratégicos ${ }^{22}$.

Analizando otro aspecto de la presentación de Hispania como tierra de bandidos, aún admitiendo la existencia de éstos, aunque no con la amplitud que las fuentes literarias nos quieren hacer comprender, debemos tener en cuenta el interés particular que alguno de los pretores y cónsules destinados a Hispania pudo tener en combatirles pues estos enfrentamientos podrían proporcionarles no sólo beneficios en especie sino fama y

18 Liv. XXVIII, i., 6.

Pol. $X X X V$, iv, 12

Liv. XIX, i, 24.

S.L. DYSON, op. cit., 89-100, 104

R. MACMULLEN, op. cit., 192. Sobre el establecimiento de guarniciones L. FLAM-ZUCKERMAN, art. cit., 469 . 
gloria, tan codiciadas por aquellos que querían afirmar o consolidar su proyección política, aun cuando sus acciones no fueran en aquellos momentos excesivamente relevantes ${ }^{23}$. No podemos por menos que mencionar que la acción de Cayo Mario en la Ulterior sobre los bandidos le facilitó, según T. C. Carney, su relación económica con la explotación de las minas de Sierra Morena ${ }^{24}$, área endémica del bandolerismo hispano, antiguo y moderno, mientras que para L. A. Curchin posibilitó que en Roma se "olvidara» la acusación que sobre él se había lanzado en 115 en el contexto de su tumultuosa relación con los Metelos ${ }^{25}$; si Curchin está en lo cierto en su valoración, estaríamos de nuevo confirmando la importancia que Roma concedía a la eliminación del bandolerismo y en particular de un área tan estratégica para las comunicaciones peninsulares como podía ser la del Saltus Castulonensis, donde la actividad endémica del bandidaje era capaz de dificultar enormemente las comunicaciones, tal y como se lo manifiesta Asinio Polión a Cicerón en su epístola del año $43^{26}$.

Igualmente una fuente antigua, en esta ocasión la obra de Dion Cassio, es la que nos pone en antecedentes del motivo que Julio César pudo tener - tal vez el que sus enemigos pensaban maliciosamente que tenía- para presentar como necesario e ineludible un primer ataque a las poblaciones del Mons Herminius, a las que se califica una vez más como bandidos: su pretexto era guerrear, obviamente para obtener prestigio ${ }^{27}$. Estaríamos por lo tanto, de ser cierto, ante las mismas sospechas que en varias ocasiones muy anteriores llevaron al Senado romano a dudar del grado de veracidad de la alarmante situación hispana que se quería transmitir, exageración que podía esconder una búsqueda de lucro particular, tanto de carácter político como económico ${ }^{28}$.

23 Recuérdese que se ataca a supuestos bandidos, sin mediar alteraciones por parte de los indígenas, como hace Lúculo sobre los vacceos (App. Ib, 51), Cf. L.A. GARciA MorENO, art. cit., 230-233 y W.V. HARRIS, Guerra e imperialismo en la Roma republicana (327-80 a. C.), trad. esp. Madrid 1989, en el capítulo dedicado a las actitudes romanas hacia la guerra.

24 T.C. CARNEY, A Biography of Caius Marius, Chicago $1970^{2}, 22-23$.

25 L.A. Curchin, Roman Spain. Conquest and Assimilation, Londres 1991, 41.

26 Cic., Epist. ad. Familiares $X, x \times x i, 1$ : "Minime mirum tibi debet videri nihil me scripsisse de republica, posteaquam itum est ad arma. Nam saltus Castulonensis, qui semper tenuit nostros tabellarios, etsi nunc frequentioribus latrociniis inferior factus es, tamen nequaquam tanta in mora est, quanta qui locis omnibus dispositi ab utraque parte scrutantur tabellarios et retinent»; cfr. F.A. MuÑoz, «Del Odio a la Paz de los Indígenas: Guerra y resistencia en la Hispania Meridional», $L a$ Bética en su Problemática Histórica (ed. C. González Román), Granada 1991, 251. Sobre la supuesta relación entre la dedicatoria de la Hispania Ulterior a Augusto y el bandolerismo en el área citada véase J. ARCE, «Estrabón sobre la Bética», J. González ed., Estudios sobre Urso. Colonia Iulia Genetiva, Sevilla 1989,220 , para las posturas ante el tema.

27 Cfr. S.L. DYSON, op. cit., 235.

28 Así Liv. XXXV, ii, con ocasión de la maniobra llevada a cabo por C. Flaminio en el 193 para llevar más hombres a Hispania; cfr. G. FATÁs, «Hispania de Catón a Graco», HA V, 1975, 278. 
Sea como fuere lo cierto es que la existencia del bandidaje en diversas áreas peninsulares parece algo incuestionable o cuanto menos lógico y previsible, así como que el perjuicio económico, social, militar y político que causaba debía ser enorme.

Militar porque podían hacerse fuertes tanto en áreas de llanura —sería el caso del fuerte Bergium ${ }^{29}$ o el de Complega ya citado- como de montaña, pudiendo de este modo impedir o dificultar grandemente el avance de la pretensión conquistadora - y civilizadora - romana.

Económico y social porque el mantenimiento de esta problemática podía provocar el empobrecimiento de otras gentes que podrían optar por seguir los pasos de sus atacantes, sin olvidar por supuesto el perjuicio económico causado a mercaderes y a las gentes ya integradas en el modo de vida romano, etc... ${ }^{30}$.

Político porque en no pocas ocasiones atacaban no sólo a las huestes sino a los aliados de los romanos, a los que éstos, al menos en teoría, deberían proteger, como queda de manifiesto en el caso de la acción romana contra Astapa ${ }^{31}$.

Eran en definitiva una fuente permanente de inestabilidad y preocupación.

Las acciones puestas en práctica para combatirles fueron de diversa índole, pasando del ofrecimiento de los medios precisos para llevar una existencia alejada del robo y el saqueo, esto es tierra explotable, y el asentamiento de poblaciones en el llano, esto último referido básicamente a las área del Noroeste ${ }^{32}$, al puro combate, donde en muchas ocasiones los romanos fueron superados, tanto que después de casi dos siglos de presencia continuada de Roma en la Península, áreas como el Mons Herminius o el Saltus Castulonensis se habrían mantenido como zonas donde nunca se pudo superar al hispano ${ }^{33}$.

Sin embargo y para finalizar, no puede olvidarse que únicamente conocemos la interpretación de uno de los oponentes, el romano, mientras

\footnotetext{
29 Liv., XXXIV, xxi.

3o Por ejemplo Liv., XXVIII, xxii, con el ataque a las gentes de Astapa a una caravana que viajaba con escolta, aunque cfr. A. GARCÍA Y BELLIDO, art. cit., 40, con una interpretación más relacionada con las alianzas políticas del momento en que tiene lugar el episodio referido.

31 Cfr. nota anterior.

32 Como en Dion Casio LIV, xi, 5, Agripa sobre los cántabros, o Floro II, 33, 52 y 59-60, Augusto, también sobre éstos, precisamente porque Augusto recelaba de la protección de las montañas, aunque esto último debe verse más como la unión de la resistencia a Roma y la práctica del bandidaje, Cfr. J.M. ROLDÁN, «La incidencia del ejército romano en el pobiamiento del NO de Hispania", en A. DEL CAsTILlo, Ejército y Sociedad. Cinco estudios sobre el Mundo Antiguo, León 1986, 18-23, en relación a estos episodios en particular.

${ }_{33}$ Cf. la epístola que Paulino de Nola dirige a Ausonio, 202 y ss., donde presenta al área vascona como un lugar donde habitasse latronum.
} 
que el del hispano apenas podemos entreverlo, apuntando, como ya se ha hecho, la posibilidad cierta de que el individuo al que Roma consideraba un ser despreciable, el bandido, fuera visto por los indígenas hispanos como un elemento más de su sociedad, sin definición o carga peyorativa alguna ${ }^{34}$. Es obvio por lo tanto que a distintas sociedades y culturas corresponde una definición distinta para un mismo elemento.

34 Cfr. las interesantes reflexiones de M.V. GARCIA QuINTELA, art. cit., 68-90. 